\title{
A cidade do futuro do pretérito: Rio de Janeiro, os Jogos Olímpicos de 2016 e o direito à moradia
}

The city of the future continuous: Rio de Janeiro, the Olympic

Games of 2016 and the right to housing

\section{Taísa Amendola Sanches}

taisasanches@gmail.com

Doutoranda e mestre em Ciências Sociais pela PUC-Rio.

\section{Resumo}

A partir da análise das políticas urbanas colocadas em prática pela prefeitura do Rio de Janeiro na preparação aos Jogos Olímpicos de 2016, este artigo procura analisar suas principais consequências relativas à segregação socioespacial na cidade e relacioná-las a conceitos como cidadania e direitos humanos.

Palavras-chave: Olimpíadas; remoções; segregação urbana.

\begin{abstract}
From the analysis of urban policies implemented by Rio de Janeiro City Hall in preparation for the 2016 Olympic Games, this article seeks to analyze its main consequences related to socio-spatial segregation in the city and relate them to concepts such as citizenship and human rights.
\end{abstract}

Keywords: Olympics; removals; urban segregation. 


\section{Introdução}

O tempo verbal denominado futuro do pretérito (composto) é utilizado quando queremos nos referir a um fato que poderia ter ocorrido depois de um determinado fato passado. Por exemplo: se eu tivesse ganhado na loteria, teria comprado uma casa. Escolho este tempo verbal para introduzir a discussão que será feita aqui, acerca dos efeitos sociais causados pelas políticas públicas urbanas levadas a cabo na cidade do Rio de Janeiro durante sua preparação para os Jogos Olímpicos de 2016, pois tinham como fio condutor a constante justificativa de construção de um futuro melhor. Elas buscavam devolver à cidade algumas das características e obras públicas realizadas no início do século XX, como se quisessem dizer que finalmente o futuro desejado àquela época iria chegar, evitando os erros cometidos anteriormente. Eduardo Paes, então prefeito da cidade $^{1}$, na data de inauguração da Praça Mauá (após ampla reforma), disse: "É um resgate da história. Uma cidade que olha para o futuro, mas preservando o passado". Por isso o futuro do pretérito.

Desde a data da escolha da cidade para sediar as Olimpíadas 2016, em outubro de 2009, muitas transformações foram feitas no ambiente urbano. O Rio de Janeiro adotou, a partir de então, o título de "Cidade Olímpica", que esteve presente em todas as logomarcas oficiais da cidade e serviu como guia de políticas públicas e obras desenvolvidas na cidade. A prefeitura da cidade, inclusive, criou um site na internet ${ }^{2}$ onde divulgava todas as transformações urbanas que foram feitas durante aquela gestão, que tinha por objetivo transformar a cidade e deixá-la apta a receber o evento. $\mathrm{O}$ site se tornou o meio de comunicação mais ativo da prefeitura, pois nele eram divulgados, por exemplo, projetos como Rio mais social e Cartão da família carioca, que não estavam diretamente relacionados aos jogos. O título de cidade olímpica se transformou na definição mais completa do Rio de Janeiro à época, uma vez que a cidade era então definida pelo que seria no futuro.

Situação semelhante ocorreu na Exposição Mundial sediada na cidade em 1922, e definida por Sant'Ana (2008) como "a própria materialização da efemeridade do presente, estimulada por visões e reflexões do passado" (p.13). Ser o país sede da Exposição Mundial trazia a responsabilidade de dar lugar a um dos maiores símbolos da modernidade, como aponta Benjamin (1985), e o “desejo em obter reconhecimento e status de nação símbolo de progresso, avanço e civilização apresentava-se comum a todos os expositores" (SANT'ANA, 2008, p.27).

\footnotetext{
${ }^{1}$ Eduardo Paes foi eleito em 2008 e reeleito em 2012.

2 www.cidadeolimpica.com.br 
Muitas transformações urbanas foram realizadas para a ocasião, dentre elas a derrubada do Morro do Castelo.

O Rio de Janeiro candidatou-se a sediar a Exposição Mundial desde 1861, quando foi realizada a primeira Exposição Nacional do Brasil, tentativa de "inserção do Brasil no cenário industrial internacional" (SANT'ANA, 2008, p.27). O intento de mostrar o país como inserido na modernidade industrial falhou, uma vez que "sobressaiu a atração exercida pelo exotismo cultural, pelo valor da produção agrícola, pela matéria-prima e minerais nacionais" (SANT'ANA, 2008, p.27). No entanto, a partir de tal data o país passou a ser convidado a participar das exposições mundiais.

O início do período republicano do país e da cidade do Rio de Janeiro como capital trouxe a intenção modernizadora do final do século XIX. Foi no início do século XX que Pereira Passos procurou desenhar a cidade que representaria a moderna capital do país, inspirada em Paris e evocando os mesmos dilemas que a cidade havia se deparado em seu passado. Não é por menos que esse prefeito foi posteriormente chamado de "Haussman tropical" (BENCHIMOL, 1990), uma vez que, como este, lidou com a intensificação do capitalismo e seus efeitos no espaço urbano da cidade.

As principais transformações do espaço urbano do Rio de Janeiro realizadas por Pereira Passos foram a construção da Avenida Central (hoje Rio Branco), o alargamento das ruas do centro, o calçamento com asfalto de diversas ruas da cidade, a construção da Avenida Beira Mar entre Botafogo e Flamengo, e a construção do Teatro Municipal. Segundo Abreu (1997), Passos determinou em mensagem intitulada "Embelezamento e Saneamento da Cidade", encaminhada à Câmara em setembro de 1903, diretrizes que iam de saneamento e higiene à desocupação de milhares de casas na área onde hoje localiza-se a Avenida Rio Branco.

Este foi o primeiro momento em que o investimento do capital se mostrou no espaço, e a riqueza passou a se evidenciar nele. A denominada Reforma Passos, segundo Abreu (1997) foi representativa principalmente por ser "o primeiro exemplo de intervenção estatal maciça sobre o urbano, (...) sob novas bases econômicas e ideológicas, que não mais condiziam com a presença de pobres na área mais valorizada da cidade" (p.63). Paradoxalmente, a expulsão da população pobre das áreas centrais da cidade fez com que um maior número de pessoas procurassem viver nas proximidades, o que "se constitui em exemplo de como as contradições do espaço, ao serem resolvidas, muitas vezes geram novas contradições para o momento de organização social que surge" (ABREU, 1997, p.66). Foi neste período que os morros próximos ao centro passaram a ser massivamente ocupados e consolidou-se a formação dos subúrbios 
mais próximos ao centro, como Engenho Novo, Engenho Velho e São Cristóvão. A população residente em São Cristóvão, por exemplo, passou de 22.202 habitantes em 1890, para 45.098 em 1906 (MORTARA, 1947, apud ABREU, 1997, p.67).

Mike Davis (2009) ao descrever as transformações urbanas de Los Angeles (LA) na primeira metade do século XX, mostra como essa cidade, quando comparada a outras de mesmo porte, "pode ser planejada ou projetada num sentido muito fragmentário (principalmente no nível de sua infraestrutura), mas ela é infinitamente visualizada" (p.55). O Rio de Janeiro, assim como LA, é uma cidade muito imaginada, principalmente pelo poder público e por sua elite econômica. As referências à cidade são quase sempre em relação àquilo que ela irá se tornar, ou sobre aqueles problemas que irão ser solucionados, parece que existe uma enorme dificuldade em pensar o que a cidade representa no presente.

O Museu do Amanhã e a reestruturação da Praça Mauá são significativos neste contexto de cidade do futuro. Em texto publicado em dezembro de 2015, o professor João Masao $\mathrm{Kamita}^{3}$, analisou as transformações da praça e mostrou como ela "parece recuperar o brilho do passado, do início do século 20, quando surgiu como a porta de entrada do Rio Belle Époque de Pereira Passos", mas que na ocasião de sua reinauguração emergiu "como um grande vazio estruturante", pois seu projeto foi entregue a uma parceria público-privada que levou em conta somente "as diretrizes do cálculo de eficiência político e da racionalidade instrumental da obra, o que quer dizer dos políticos de mandado e das empreiteiras e seus consórcios".

Inaugurado em dezembro de 2015 na Praça Mauá, o museu reverencia o futuro. A preocupação com a estética desta obra é fundamental. Por não apresentar grandes exposições em seu interior, a construção do museu é futurística, negando o passado do local onde está construído. Por outro lado, à população mais pobre da cidade cabe o passado. Ao mesmo tempo que a cidade tem sua imagem voltada ao futuro, tenta-se manter vivo o espírito comunitário atribuído às favelas e à população pobre do início do século XX. Como se a população mais pobre pudesse sobreviver na cidade imaginada apenas mantendo harmoniosos costumes e revitalizando as tradições do samba.

Orlando Alves dos Santos Junior (2015), que denominou as transformações do Rio de Janeiro dos jogos de "modernização neoliberal", acredita que este processo "parece se aproximar das práticas patrimonialistas, que tanto marcam a história da cidade do Rio de Janeiro, e se distanciar da gestão democrática associada ao ideário do direito à cidade” (p.479).

\footnotetext{
3 Texto publicado em 16 de dezembro de 2015, disponível no site http://www.vitruvius.com.br/revistas/read/arquitextos/16.187/5885. 
A cidade permaneceu nesse meio caminho entre o futuro glorioso e o passado visto com saudosismo, que remete às tradições do samba, da malandragem. Nesse passado, a vida nas favelas remetia à harmonia, situação que era confortável ao Estado por manter relações de clientelismo e patronagem com seus moradores.

Em alguma medida, a forma como o investimento na cidade se produziu no Rio de Janeiro durante a preparação para os jogos olímpicos se aproxima também daquele verificado no período desenvolvimentista (1946-1964). Ainda que, naquela época, a principal orientação econômica estivesse relacionada à industrialização do país, alavancada por políticas protecionistas de substituição de importações. A preocupação latente em modernizar o país esteve presente nos projetos de habitação social da época, “introduzindo novos hábitos e um modo de vida 'moderno' que romperiam com o atraso do país, expresso no subdesenvolvimento" (BONDUKI, 2013, p.138). Foram construídos conjuntos habitacionais que seguiam ideais de modernização, como o Edifício Pedregulho, em São Cristóvão, em 1947. Em ambos os casos, os projetos de habitação social se encontram entre a melhoria do aspecto da cidade, excluindo-se os mais pobres de habitações precárias que destoam do cenário, e projetos de baixo custo que maquiam a realidade da população que neles habita.

Talvez seja possível afirmar que o Rio de Janeiro, por ser cenário natural reverenciado mundialmente, se compare à Veneza descrita por Simmel (2003). Em ambas se busca na beleza estética uma definição de cidade, o que acaba por torná-las superficiais, “como se só as camadas superiores da alma, que se limitam a captar reflexos, a fruir passivamente, respirassem ainda, enquanto a sua realidade plena permanece à margem como que num sonho indolente" (p.126).

Assim como ocorreu à época da Exposição Mundial de 1922, o Rio de Janeiro se candidatou a sediar um evento de alcance mundial novamente, tendo sido eleita em 2009 para organizar os jogos em 2016. E da mesma forma que ocorreu no início do século XX, na época de preparação para os jogos a cidade passou por intensas transformações urbanísticas, que afetaram em especial a população mais pobre da cidade. O que se indica pelas políticas urbanas e habitacionais da prefeitura do Rio de Janeiro à época, como veremos a seguir, é que a cidade era percebida como uma empresa a ser gerida, negligenciando "as singularidades da vida urbana, os modos de viver da cidade, o habitar propriamente dito" (LEFEBVRE, 1991, p.57). 


\title{
A cidade olímpica e a gestão de alto desempenho: padrões de segregação urbana na cidade ressignificados
}

\begin{abstract}
A administração da Prefeitura do Rio de Janeiro que teve início em 2009 decidiu por outro caminho: se guiar pelas melhores práticas de gestão (...). A chamada Gestão de Alto Desempenho da Prefeitura estava pautada em três valores fundamentais: foco em resultados, pragmatismo e disciplina. Estas três características deveriam ser reconhecidas em cada decisão tomada. Ou seja, ao invés de agir somente pela necessidade ou intuição, a Prefeitura passou a agir com método. (GESTÃO DE ALTO DESEMPENHO, Prefeitura do Rio de Janeiro 2009-2012)
\end{abstract}

O trecho acima, elaborado pela gestão de Eduardo Paes na prefeitura do Rio de Janeiro, visava demonstrar que o cumprimento das metas propostas para o período de 2009 a 2012 seria inspirado em práticas de gestão mais comuns ao setor privado. O relatório é um importante documento que demonstra quais eram as diretrizes para os desenhos urbano e habitacional da cidade durante a preparação para os jogos olímpicos de 2016.

Orlando Alves dos Santos Jr. (2015) viu neste projeto um novo ciclo de mercantilização do espaço urbano, na medida em que a cidade passou a ser gerida de forma empresarial, quando inseriram áreas e serviços públicos da cidade "aos circuitos de valorização do capital" (SANTOS, 2015). O autor sugere que se colocou em curso um "processo de intensificação da elitização da cidade", tanto por conta da "transferência forçada de ativos sob a posse ou controle das classes populares para setores do capital imobiliário", quanto pela "criação de novos serviços e equipamentos urbanos que passariam a ser geridos pela iniciativa privada" (SANTOS, 2015).

Na mesma direção, Gabriel Feltran (2014) apontou para o caráter de inclusão social pelo mercado das políticas públicas atuais. Para ele, "a habitação social contemporânea é a ponta da operação de mercados financeiros transnacionais" (p.507), sendo fundamental "associar ao dispositivo mercantil uma cunha de destituição do "direito a ter direitos"” (p.508), no sentido em que o direito à habitação é dado via aquisição de imóvel, mas não oferece aos beneficiários um real acesso à vida pública que a cidade possibilita. Veremos como os planos e projetos, leis e decretos da prefeitura e do governo federal influenciaram o processo de segregação urbana no Rio de Janeiro a partir dessas perspectivas.

O Plano Estratégico que guiou a gestão da prefeitura de Eduardo Paes entre 2013 e 2016 se baseou nas políticas "exitosas" implementadas no primeiro mandato, e trouxe ao debate a questão habitacional - que não estava presente no relatório dos primeiros anos. O Plano 
propunha a construção de 100 mil residências e a redução em 5\% da área do município ocupada por favelas, mas não explicava quais as atividades seriam desenvolvidas nesse sentido. A palavra habitação aparecia menos de 10 vezes no documento, e a palavra favela, quatro vezes. O programa Minha Casa Minha Vida não era mencionado.

Outro documento oficial importante para desenhar a conjuntura habitacional e urbana do Rio de Janeiro foi o decreto número 34.522, de outubro de 2011, que aprovava "as diretrizes para a demolição de edificações e relocação de moradores em assentamentos populares”. Esse decreto estabelecia "a necessidade de atualizar e uniformizar os procedimentos da administração municipal para a desocupação de áreas em assentamentos populares, necessárias à implantação de projetos de interesse público", e apresentava o PMCMV como alternativa de relocação das famílias removidas.

Esses documentos apresentaram as políticas públicas urbanas colocadas em prática na cidade, demonstrando que os dois mandatos de Eduardo Paes trouxeram o "problema favela" de volta ao debate. Quando assumiu, em 2009, o prefeito deu uma entrevista à revista Veja, na qual dizia que as remoções de favelas seriam a única solução em alguns casos. Ele propôs, naquela ocasião, que os moradores removidos de favelas fossem realocados no subúrbio da cidade:

Tem linha de trem, metrô, hospital, escola, rua asfaltada, água, esgoto e luz. Os moradores dessas regiões reclamam que ali só há intervenções para melhorar as favelas e que o bairro em si está completamente abandonado. É verdade. O subúrbio, que já foi o símbolo de um Rio pujante, se deteriorou. Ali, a lógica do processo está invertida: áreas degradadas, como as favelas, vão ocupando e destruindo o tecido urbano consolidado. Meu sonho como prefeito é inverter esse fluxo, investir nos bairros e fazer com que a lógica da cidade formal passe a influenciar as áreas onde a favela avançou, possibilitando que haja um adensamento populacional civilizado. (ENTREVISTA com Eduardo Paes, Revista Veja, maio de 2009)

Os investimentos da prefeitura em habitação, durante essa gestão, foram feitos no sentido de realizar o "sonho" mencionado pelo prefeito, e a legislação da cidade foi alterada abrindo espaço para a realização das transformações desejadas. O Plano Diretor da cidade do Rio de Janeiro, por exemplo, aprovado em 2011, previa, em seu Artigo 15, segundo parágrafo, que

Os moradores que ocupem favelas e loteamentos clandestinos nas áreas referidas no parágrafo anterior ${ }^{4}$ deverão ser realocados, obedecendo-se às

\footnotetext{
${ }^{4}$ Ou seja: áreas de risco; faixas marginais de proteção de águas superficiais; faixas de proteção de adutoras e de redes elétricas de alta tensão; faixa de domínio de estradas federais, estaduais e 
diretrizes constantes do art. 201 desta Lei Complementar, do artigo 429 da Lei Orgânica do Município, observado os dispositivos do Art. $4^{\circ}$ da Medida Provisória $\mathrm{n}^{\mathrm{o}} 2.220$, de 4 de setembro de 2001.

O art.201, mencionado acima, previa que a política de habitação deveria "produzir novas soluções habitacionais" e "incentivar a formação de parcerias com entidades públicas e privadas". Portanto, os moradores de favelas e loteamentos clandestinos, deveriam, segundo o Plano Diretor da cidade, ser removidos e realocados em soluções habitacionais que previam a parceria público-privada.

Se nos anos 1990 e 2000 as remoções de favelas foram estigmatizadas pelos movimentos sociais e postas de lado pelo poder público, na gestão de Eduardo Paes voltaram a se configurar como política habitacional, realizada em parceria com o governo federal, através do PMCMV. Estima-se que 67.000 pessoas foram removidas entre 2009 e 2013 (AZEVEDO \& FAULHABER, 2015, p.36), o que representava cerca de $1 \%$ da população da cidade na época. Este representa outro ponto de semelhança com Pereira Passos, que removeu 20.000 pessoas, ou cerca de $2,5 \%$ da população.

No Rio de Janeiro, o investimento no ambiente urbano devido aos jogos olímpicos foi enorme, e seus impactos na urbanização da cidade seguiram o mesmo padrão, uma vez que absorveram "as mercadorias excedentes que os capitalistas não param de produzir em sua busca de mais-valia" (HARVEY, 2014, p.33). Nas margens da cidade, os efeitos do investimento do excedente de capital produziram outro fenômeno descrito por Harvey: a criação de uma "vida sem alma”, através da construção de empreendimentos monótonos de moradia que pretendiam vender uma "réplica customizada da vida nas cidades" (HARVEY, 2012, p.41). Foram construídos empreendimentos imobiliários que buscavam replicar bairros inteiros, como o Bairro Carioca, em Triagem, parte do programa Minha Casa Minha Vida.

Os conjuntos habitacionais construídos em parceria com o PMCMV revelaram a relação entre política pública de habitação social e mercado existente no país, despontando o que Shimbo (2010) denomina como habitação social de mercado. A localização periférica de alguns conjuntos habitacionais, a baixa qualidade construtiva e a adoção do modelo "condomínio" são algumas das consequências de um acordo entre governo e setor privado, em que a busca de lucro pelas empresas tem influência nas suas escolhas. A opção pela forma de

municipais; áreas de Preservação Permanente e Unidades de Conservação da Natureza; áreas que não possam ser dotadas de condições satisfatórias de urbanização e saneamento básico; áreas externas aos ecolimites, que assinalam a fronteira entre as áreas ocupadas e as destinadas à proteção ambiental ou que apresentam cobertura vegetal de qualquer natureza; vãos e pilares de viadutos, pontes, passarelas e áreas a estes adjacentes; e áreas frágeis de encostas, em especial os talvegues, e as áreas frágeis de baixadas. 
“condomínios", por exemplo, vai além da oferta de um estilo de vida. Para as empreiteiras, esse tipo de construção as exime dos custos da manutenção dos edifícios após a entrega aos moradores. Após mudarem aos conjuntos, são os moradores que se responsabilizam pela sua gestão.

No Rio de Janeiro, grande parte dos conjuntos do PMCMV construídos durante a preparação da cidade para os jogos localiza-se em áreas afastadas do centro da cidade. As empresas buscaram terrenos mais baratos por oferecerem maiores chances de lucro, e a população foi realocada em locais distantes e sem infraestrutura urbana. Não foram levados em conta os tipos de segregação e desigualdades presentes na cidade. Oferecer condomínios padronizados a diferentes populações e inseri-las em bairros também carentes de infraestrutura denuncia um tipo de visão que homogeneíza os problemas das periferias. Como solução, são oferecidas "políticas redistributivas para espaços periféricos (...) que ficam perdidas entre a evidente insuficiência do que é realizado e a irrelevância das iniciativas diante do que deveria (e até poderia) ser feito" (MARQUES, 2005, p.54). O acesso à cidade oferecido aos mais pobres, portanto, através da construção de conjuntos habitacionais homogêneos, sendo a maioria nas fronteiras urbanas, aumentou a segregação social.

Essa reflexão leva a questionar se os empreendimentos do PMCMV podem ser caracterizados da forma como Agier (2015) classifica os campos de refugiados e acampamentos informais. Como espaços "colocados em heterotopia", marcados por "separar, retardar ou suspender todo reconhecimento de uma igualdade política entre seus habitantes e cidadãos comuns" (p.46). Porque, a efetivação destas políticas habitacionais teve efeitos também na forma urbana do Rio de Janeiro. O "subúrbio pujante" do Rio de Janeiro, evocado na fala do prefeito Eduardo Paes, se estabeleceu como um emaranhado de conjuntos habitacionais, devido não só às ações da gestão daquele prefeito, mas de um histórico de políticas habitacionais que levaram a isso. Na antiga área industrial da cidade, próximo à Manguinhos, existem diversos conjuntos, como o Bairro Carioca, com 10.000 unidades habitacionais, e a Nova CCPL, na área da antiga fábrica da $\mathrm{CCPL}^{5}$, com 728 unidades habitacionais; além daqueles mais antigos, que pertencem ao Complexo de Manguinhos: CHP2, com uma população de 3.908 pessoas, o Conjunto Habitacional Nelson Mandela, com 3.101 moradores, e o Conjunto Habitacional Samora Machel, com 3.188 habitantes, entre outros.

\footnotetext{
${ }^{5}$ Disponível em: http://www.rj.gov.br/web/seobras/exibeconteudo?article-id=2103491. Acesso em abr 2015.
} 


\section{Notas sobre moradia e direitos humanos}

No Brasil, habitação e cidadania andam de mãos dadas. $\mathrm{O}$ direito à habitação no país nasceu como direito social, com a Constituição de 1988. Ainda que a ideia de direito à moradia tenha sido uma das garantias previstas na Declaração dos Direitos Universais de $1948^{6}$, no Brasil o tema começa a ganhar corpo nessa Constituição, quando é lançada a ideia de política urbana, que considera a existência de funções sociais para as cidades. Ou seja, a partir desta legislação, passa-se a encarar o espaço urbano como um direito. Prover habitação social passa a ser condição para o usufruto da cidade e, por que não, de acesso à cidadania.

Antes dessa Constituição, a preocupação estatal em construir casas para a população necessitada foi uma questão apresentada somente durante o governo de Getúlio Vargas. A opção popular de residências vinha do setor privado, com a construção de vilas operárias, que geravam lucros e eram estimuladas pelo governo através de isenção de impostos. A partir da Revolução de 1930, o governo populista traz a questão da necessidade de oferecer propriedade de moradia e alimentação adequada aos trabalhadores.

Segundo Bonduki (2013), que analisou as origens da habitação social no Brasil, esse governo via na oferta de moradia popular uma "condição básica de reprodução da força de trabalho e, portanto, como fator econômico na estratégia de industrialização do país". Além disso, havia o entendimento que a oferta de moradia seria essencial para a criação de trabalhadores "padrão", que significavam sua "base de sustentação política” (p.73).

Nota-se que as políticas habitacionais deste período são direcionadas aos trabalhadores assalariados, pois o direito à habitação e a serviços sociais básicos era destinado àqueles com carteira assinada. Nos anos 1940, foram construídos 618 condomínios financiados pelos Institutos de Aposentadorias e Pensões, somente no Rio de Janeiro, capital do país na época (BONDUKI, 2013, p.105). O beneficiamento de trabalhadores formais versus a forma como era tratada a habitação aos favelados mostra "uma linha divisória entre os cidadãos com direitos sociais, entre os quais os trabalhadores assalariados, e os subcidadãos, que não tinham lugar na nova ordem social” (BONDUKI, 2013, p.109). Aos favelados, restaria uma educação civilizadora - dada através da moradia em locais dentro da ordem - que os prepararia para a

\footnotetext{
${ }^{6}$ Artigo XIII 1. Toda pessoa tem direito à liberdade de locomoção e residência dentro das fronteiras de cada Estado. Artigo XXV -1. Toda pessoa tem direito a um padrão de vida capaz de assegurar a si e a sua família saúde e bem estar inclusive alimentação, vestuário, habitação, cuidados médicos e os serviços sociais indispensáveis, e direito à segurança em caso de desemprego, doença, invalidez, viuvez, velhice ou outros casos de perda dos meios de subsistência fora de seu controle.
} 
vida social. Em 1964, o governo federal cria o Banco Nacional de Habitação - BNH, responsável por financiar a construção de habitações populares de forma a "resolver o 'problema-favela' e 'aquecer a economia", unindo, dessa forma, "a fome com a vontade de comer" (BRUM, 2012, p.85).

A partir de 1988, através da Constituição democrática, os avanços nesta área voltam a ter sentido. No entanto, somente em 2001, com a declaração do Estatuto da Cidade, passa a ser oferecido respaldo constitucional a uma nova maneira de realizar o planejamento urbano, sendo seu papel garantir o cumprimento da função social da cidade e da propriedade urbana. Isso significa o estabelecimento de "normas de ordem pública e interesse social que regulam o uso da propriedade urbana em prol do bem coletivo, da segurança e do bem-estar dos cidadãos, bem como do equilíbrio ambiental" ( $\left.\operatorname{art} .1^{\circ}\right)$. Desde então, o debate acerca do direito à cidade passa a tomar corpo no Brasil, e a relação entre local de moradia e acesso à cidadania passam a fazer parte da pauta.

Roberto DaMatta (1991) utiliza duas categorias sociológicas - a casa e a rua - para compreender a construção da cidadania no Brasil. A utilização dos conceitos de esfera privada e pública são fundamentais na análise do autor. No livro, se analisa de que maneira a sociedade brasileira se relaciona com os espaços público e privado, contrapondo com a relação estabelecida entre as mesmas categorias nos Estados Unidos. DaMatta (1991) resume bem como deve ser encarado, idealmente, o exercício da cidadania: "como cidadão eu pertenço a um espaço eminentemente público e defino o meu ser em termos de um conjunto de direitos e deveres para com outra entidade também universal chamada "nação"” (p.67).

Uma das prerrogativas para o exercício da cidadania seria, pois, a igualdade. Para DaMatta (1991), uma sociedade igualitária é aquela em que, no espaço público, todos são vistos como indivíduos, e não como pessoas. Não deve existir, portanto, diferenciações em nenhuma hipótese. Ser cidadão é possuir os mesmos direitos e deveres de todos os demais indivíduos pertencentes a uma mesma sociedade.

A desigualdade brasileira e o consequente desmantelamento do exercício de um "tipo ideal" de cidadania no país, se dariam por conta da expressiva personificação do espaço público a que estamos habituados. DaMatta (1991) mostra como a sociedade brasileira está acostumada e tem necessidade de hierarquizar as relações sociais quando busca a obtenção de direitos que seriam supostamente comuns a todos. $\mathrm{O}$ autor caracteriza a sociedade brasileira como extremamente relacional, em que as relações sociais são mais importantes do que a participação em uma totalidade, necessária para a participação cidadã. 
A partir do exposto, pode-se apontar para dois lados: um deles mostra o vazio de cidadania daqueles que não possuem moradia, e o outro aponta para a cidadania diferenciada entre bairros de elite e populares. No segundo, a relação com a tipificação de DaMatta demonstra como a relações sociais são hierarquizadas a partir do local de moradia.

\section{Conclusões}

O projeto de reconstrução do antigo subúrbio industrial do Rio de Janeiro pela gestão de Eduardo Paes, aproveitando-se dos insumos gerados pela preparação da cidade para os Jogos Olímpicos de 2016, mostrou como a cidade se apodera das significações políticas e as expõe em edifícios. As políticas habitacionais segregacionistas levadas a cabo hoje se expressam nestes conjuntos já decadentes e no território cada vez mais polarizado. Como disse Lefebvre, “a estrutura social está presente na cidade, é aí que ela se torna sensível, é aí que significa uma ordem. Inversamente, a cidade é um pedaço do conjunto social; revela porque as contém e incorpora, na matéria sensível, as instituições, as ideologias" (1991, p.60).

A formação territorial do Rio de Janeiro, cuja pesada herança ainda hoje reflete padrões clientelistas e escravistas, vai na contramão daquela que foi uma das condições para a formação das comunas que originaram as cidades. Max Weber (1999), quando tratou do surgimento das cidades medievais e da antiguidade, procurou expor como sua existência decorria de certa organização estrutural, baseada no território. A delimitação do espaço em que os mesmos códigos valem a todos os indivíduos que dentro dele viviam era condição fundamental para a garantia das características de um tipo ideal de cidade. Viver sob códigos comuns em um território delimitado seria condição fundamental para a existência das cidades. Seria através do pertencimento a um mesmo código moral que se normatizaria a igualdade na cidade. $\mathrm{O}$ conceito de cidadania estaria, assim, imbricado ao de igualdade, uma vez que ele explicita o papel de cada indivíduo perante o acordo associativo da cidade.

Para DaMatta, o conceito de cidadania implica "de um lado, a ideia fundamental de indivíduo (e a ideologia do individualismo), e, de outro, regras universais (um sistema de leis que vale para todos em todo e qualquer espaço social)" (1997, p.66). Analisar como este conceito é colocado em prática, implica também compreender que ele é "socialmente institucionalizado" por leis e "moralmente construído" pela cultura (DaMatta, 1997, p.67). O autor mostra que uma sociedade igualitária é aquela onde, no espaço público, todos são vistos como indivíduos e não como pessoas. Não deve existir, portanto, diferenciações em nenhuma 
hipótese. Ser cidadão é possuir os mesmos direitos e deveres de todos os demais indivíduos pertencentes a uma mesma sociedade.

Isaac Joseph, indo pelo mesmo caminho, acredita que a oferta de espaço público não é suficiente para levar à cidadania: "a passagem da urbanidade à cidadania não corresponde a uma consequência natural" (2005, p.96). O autor considera que as cidades, em sua natureza, contêm a ideia de integração, na medida que unem indivíduos diferentes sob os mesmos códigos, e, por conseguinte também segregam, quando superpõem e amontoam a população em um mesmo território. Unindo a proposta de Joseph, pode-se trazer o que Marcuse (1997) considera a respeito de segregação. Para este autor, diversos tipos de separação espacial reforçam a segregação social, uma vez que "integração significa algo mais que não-segregação: significa uma interação positiva, uma mistura, uma comunicação em andamento entre grupos" (1997, p.251).

É nesta medida que buscamos compreender em que grau a cidade do Rio de Janeiro “integra, desagrega, segrega e separa”, para usar os termos de Marcuse (1997), as classes populares em um contexto de transformação urbana radical, mesmo quando comparada a outras políticas urbanas realizadas no passado. 


\section{Referências bibliográficas}

ABREU, Maurício de Almeida. A Evolução Urbana do Rio de Janeiro. Rio de Janeiro: IPLANRIO, 1997.

AZEVEDO, Lena. FAULHABER, Lucas. SMH 2016: remoções no Rio de Janeiro Olímpico. Rio de Janeiro: Mórula, 2015.

BENCHIMOL, Jaime Larry. Pereira Passos: um Haussmann tropical: a renovação urbana da cidade do Rio de Janeiro no início do século XX. Rio de Janeiro: Secretaria Municipal de Cultura, Turismo e Esporte, 1990.

BENJAMIN, Walter. Paris, capital do século XIX. In: KOTHE, F. R. (org.). Walter Benjamin. São Paulo: Ática, 1985.

BONDUKI, Nabil. Origens da habitação social no Brasil: arquitetura moderna, lei do inquilinato e difusão da casa própria. São Paulo: Estação Liberdade, 2011.

CARDOSO, A. et al. Quando um direito vira produto: impactos do programa minha casa minha vida na cidade do Rio de Janeiro. Anais... Simpósio Nacional de Geografia Urbana, XVIII. UERJ, 2013.

DAVIS, Mike. Cidade de Quartzo: escavando o futuro em Los Angeles. São Paulo: Boitempo, 2009.

ENTREVISTA com Eduardo Paes. Revista Veja, maio de 2009. Disponível em http://pmdb.org.br/noticias/chega-de-demagogia-diz-eduardo-paes-em-entrevista-a-veja/. Acesso em: 6 nov de 2018.

FELTRAN, Gabriel. O valor dos pobres: a aposta no dinheiro como mediação para o conflito social contemporâneo. Caderno CRH, Salvador, v.27, n.72, p.495-512, 2014.

GESTÃO DE ALTO DESEMPENHO, Prefeitura do Rio de Janeiro 2009-2012. Documento de trabalho.

HARVEY, David. O direito à cidade. São Paulo, Revista Lutas Sociais, n.29, p.73-89, 2012.

2014.

Cidades rebeldes: do direito à cidade à revolução urbana. São Paulo: Martins Fontes,

LEFEBVRE, Henri. $O$ direito à cidade. Trad. Rubens Eduardo Frias. São Paulo: Editora Moraes, 1991.

MARCUSE, Peter. The enclave, the citadel, and the ghetto. What has changed in the PostFordist U.S. City. Urban Affairs Review, v.33, n.2, Sage, 1997.

MARQUES, Eduardo. Elementos conceituais da segregação, da pobreza urbana e da ação do Estado. In: MARQUES, Eduardo \& TORRES, Haroldo (org.). São Paulo: segregação, pobreza e desigualdades sociais. São Paulo: Editora Senac, 2005. 
SANT'ANA, Thais Rezende da Silva de. A Exposição Internacional do Centenário da Independência: modernidade e política no Rio de Janeiro do início dos anos 1920. Unicamp. Dissertação de mestrado apresentada ao Departamento de História. Campinas, 2008.

SANTOS JUNIOR, Orlando Alves dos. Governança empreendedorista: a modernização neoliberal. In. RIBEIRO, Luiz Cesar de Queiroz. (Ed.) Rio de Janeiro: transformações na ordem urbana. Rio de Janeiro: Editora Letra Capital, 2015.

SHIMBO, Lucia Zanin. Habitação social, habitação de mercado: a confluência entre Estado, empresas construtoras e capital de mercado. USP. Tese de doutorado apresentada à Coordenação de Pós-Graduação em Arquitetura e Urbanismo. São Carlos, 2010.

SIMMEL, Georg. Veneza. Revista crítica de ciências sociais. n.67, 2003.

WEBER, Max. Economia e Sociedade: fundamentos da sociologia compreensiva. Brasília: Editora UNB, 1999. 